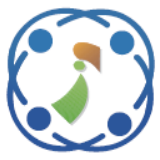

\title{
A Novel Imperialistic Competitive Algorithm for Unit Commitment with Wind Generation
}

\author{
Saranya Sudhakar $^{1} \quad$ Saravanan Balasubramanian $^{1 *} \quad$ Sanjeevikumar Padmanaban $^{2}$ \\ ${ }^{1}$ School of Electrical and Electronics Engineering Affiliation, VIT University, \\ Tamilnadu, Vellore, India \\ ${ }^{2}$ Department of Electrical and Electronics Engineering, University of Johannesburg, \\ Auckland Park 2006, South Africa \\ * Corresponding author's Email: bsaravanan@vit.ac.in
}

\begin{abstract}
The integration of wind power to the grid is essential to meet the growing power demand and possess a challenge to unit commitment to meet the load demand at low cost for scheduling the generating units. A new imperialistic competitive algorithm (ICA) has been developed for the above mentioned unit commitment problem for solving deterministic and stochastic condition. This imperialistic competitive algorithm has been developed with constraints, including generation limits, start up and shut down cost, minimum up and downtime along with ramp constraint. The ICA has been studied initially on the 10 units 24 hour system and 40 units 24 hour system for the deterministic load. Later, a wind generator has been added to the 10 units 24 hour system with wind data for 24 hours and the results are compared with genetic algorithm (GA), particle swarm optimization (PSO), hybrid particle swarm optimisation (HPSO), shuffled frog leaping algorithm (SFLA), invasive weed optimization (IWO). The comparison result is presented in this paper and it shows that the ICA gives optimized fuel cost of $\$ 482246.2$ which is less than the LR, GA, BFOA, SFLA, IWO for stochastic unit commitment.
\end{abstract}

Keywords: Deterministic load, Imperialistic competitive algorithm stochasticity, Unit commitment, Wind generator, Ramp constraint, minimum up and down time constraint.

\section{Nomenclature}

$N_{i m p} \quad$ Number of imperialists

$N_{c o l} \quad$ Number of colonies

$N_{i} \quad$ Number of initial colonies of imperialist i

$P_{i} \quad$ Normalized power of imperialist $\mathrm{i}$

$I \quad$ Index of generator unit

$P_{o s C d}$ Position of a colony at the current decade in a specific empire

$P_{o s C d+1}$ Position of a colony at the next decade $\mathrm{n}$ in a specific empire

$P_{\text {osld }} \quad$ Position of $\mathrm{d}^{\text {th }}$ imperialist

rand Random number

$\beta \quad$ Assimilation weight factor

$C F_{i, t} \quad$ Operating cost of unit I at hour $\mathrm{t}$

$P_{i, t} \quad$ Power produced by unit I at hour $\mathrm{t}$

$v_{i, t}=1$ if unit $\mathrm{i}$ is on at hour $\mathrm{t}$

$v_{i, t}=0$ if unit $\mathrm{i}$ is off at hour $\mathrm{t}$
$\operatorname{CSC}_{i} \quad$ Cold startup cost of unit i

$P_{i, \text { min }} \quad$ The minimum power produced by unit i

$P_{i, \max } \quad$ The maximum power produced by unit $\mathrm{i}$

$\mathrm{S}_{\mathrm{i}, \mathrm{t}} \quad$ Startup cost for unit $\mathrm{i}$ at time $\mathrm{t}$

$P_{\mathrm{i}, \mathrm{t}} \quad$ Power produced by each unit $\mathrm{i}$ at time $\mathrm{t}$

$T_{\text {ui }} \quad$ Up time of unit i

$T_{\mathrm{di}} \quad$ Down time of unit $\mathrm{i}$

$T_{i, t-1}$ on $\quad$ On time for unit at $\mathrm{t}-1$ hour

$T_{i, t-1}$ off Off time for unit at $\mathrm{t}-1$ hour

$\mathrm{P}(\mathrm{i}, \mathrm{t}-1)$ Power produced by each unit i at $\mathrm{t}-1$

$U R(i) \quad$ Ramp up limit for unit i

$D R(i) \quad$ Ramp down limit for unit i

$i c_{k} \quad$ Cost of the $\mathrm{k}^{\text {th }}$ imperialist

$I C_{i} \quad$ Normalized cost

$T_{c n} \quad$ Total cost

$\xi \quad$ Positive number which is less than 1

$w_{j t} \quad$ The power dispatch of wind at time $\mathrm{t}$

$H S C_{i} \quad$ Hot startup cost of unit i 


\section{Introduction}

Unit Commitment (UC) is a complex decision making optimization problem used for scheduling the generating units for every hour of the horizon to meet the load demand at low cost subjected to different constraints and environment [1]. Now-adays, integration of wind energy sources in a thermal power system is becoming more and more popular due to its low operating cost and low environmental pollution. The increasing penetration of wind energy to the power system brings uncertainty in the day ahead scheduling of generating units [2].

Many significant research has been carried out to address this uncertainty in unit commitment. The most common approach is the stochastic unit commitment (SUC) [3], a scenario generation method to obtain the random factors, but results in large computation time. Scenario reduction techniques have been introduced to exclude the improbable scenarios to overcome the above problem. But it is more challenging task to cover all possible scenarios that may lead SUC to costly solutions [4-12]. The chance constraint unit commitment (CCUC) is studied [13], to overcome the above issue, it converts the uncertainty distribution into the probabilistic distribution, which is computationally challenging. Unlike robust unit commitment (RUC), two stage CCUC is developed [14] to circumvent this issue. However, RUC needs a deterministic set of uncertainty rather than the probabilistic approach to achieve operational feasibility. This method suffers from increased conservatives in solution [15-17]. The min- max regret approach [18], Interval number programming method [19] overcomes the above problem as well as increases the robustness of the solution, has the disadvantage of high computation time. Interval Unit Commitment (IUC) is studied, to establish uncertainty limit with upper and lower bound as in RUC. In this approach central forecast is considered to achieve optimality with a feasible solution than SUC [20-21]. Another modeling the robust risk constrained unit commitment (RRUC) focusses on size of uncertainty limit [22]. Some of the studies deal with hybrid modeling approaches like unified stochastic and robust unit commitment, hybrid stochastic/interval unit commitment to improve robustness and accuracy [23, 24]. This paper is mainly focused on optimization of power systems for planning the scheduling of units as well as economic dispatch of scheduled units. This work putting in light on the decision problem of unit commitment with wind generation in particular by considering ramping constraint as one of the approaches. At first the ramp constraints are calculated for thermal unit as $60 \%$ of rated capacity so that the maximum and minimum ramp rates of the system are obtained to cover the fluctuations of the wind power. The wind unit will be incorporated only when generated wind power satisfies the ramp limit such that the system uncertainty is managed [25].

In literature, different solutions using numerical optimization techniques have been proposed to solve the unit commitment problem such as dynamic programming [26], priority list [27], Bender decomposition [28], mixed integer programming [29], exhaustive enumeration and branch and bound method [27, 32] etc., Bio inspired techniques using genetic algorithm [33], particle swarm optimization (PSO) [34], bacterial foraging problem (BFOA) [35], ant colony optimization (ACO) [36], simulated annealing [37], shuffled frog optimization algorithm (SFLA) [38], invasive weed optimisation [51], etc. The exhaustive enumeration method is a simple combination technique, suffers with high computation time [27]. Lagrange Relaxation (LR) is fast and flexible, but it suffers in sub optimality [27, 29-31]. Branch and bound is a general optimization algorithm used in discrete and combinatorial optimization [27, 32]. Priority list is fast, but highly heuristic and gives more operating cost [27]. Dynamic Programming is good for a variety of sizes, but more complex hence the computation time more [27]. A new algorithm called an imperialistic competitive algorithm (ICA) inspired by imperialistic competition, which causes the colonies to converge to global minimum cost function [3950] has been attempted in this research

In this paper imperialistic competitive algorithm (ICA) [8-9] is used to solve the unit commitment problem. Atashpaz - Gargariin (2007) introduced an optimization based on the concept of dividing the countries into two categories such as imperialism and the colonies. Based on the best objective function imperialists and the colonies are selected. The both imperialist and colonies form empires. Then the imperialistic competition begins to obtain the global optimal solution. ICA has been implemented in solving various optimization problems like DG planning [39], template matching [40], optimal design of plate-fin heat exchangers [41] electromagnetic problems [42], power system stabilizer design [43], linear induction motor design [44], economic dispatch [45] and model reduction of a detailed transformer model [46]. Recently Imperialist Competitive algorithm [47] has also been implemented for solving unit commitment with a 
thermal unit alone. In this proposed paper ICA has been tested for integration of wind-thermal unit commitment. Initially in this paper imperialist competitive algorithm is tested on 10 unit 24 hour system and results are compared with other algorithms like LR, GA, SFLA, and BFOA. Later, a wind generator is added to the system. The whole system becomes stochastic, but considering it to be a deterministic load, results are obtained.

The final result is obtained after unit commitment on the system, focus on the generation level (mostly in Megawatts) and the number of generators on. The binary variables $\left(\begin{array}{lll}0 & \text { or } 1\end{array}\right)$ determine if the generating systems are on or off. In addition, the fuel price at each hour is calculated using economic dispatch. The final summation of the fuel prices at the end of the last hour is calculated. In next case wind data's are added to generation side and the unit commitment done with imperialistic competitive and fuel cost are calculated in the last section.

\section{Problem formulation}

The most prominent objective of power system is the minimization of the overall fuel cost [25]. It plays a vital role in decision making for the efficient functioning of the overall system which also includes the startup cost as in Eq. (1).

$$
\min \sum_{i=1}^{N} \sum_{t=1}^{T}\left[C F_{i, t}\left(P_{i, t} v_{i, t}\right)+S_{i, t} v_{i, t}\right]
$$

The first term $C F_{i, t}$ signifies the cost of production of each unit $i$ for every hour $t$. The second term of the objective function denotes $S_{i, t}$ the startup cost of the units at that particular time.

\subsection{Constraints}

There are few constraints considered in carrying out the operation of this system and the constraints considered in this work are given below:

\subsubsection{Generation constraints (Limits)}

The power produced for each unit $i$ should be within the limits specified for each generator. The minimum and maximum power limits for each generator is taken into account [25]. This constraint is put in the equation form as follows in Eq. (2).

$$
\begin{gathered}
v_{i, t} P_{i, \min } \leq P_{i, t} \leq v_{i, t} P_{i, \max } \\
\text { Where } \quad i=1,2 \ldots N \text { and } t=1,2 \ldots T
\end{gathered}
$$

\subsubsection{Minimum up and down time constraints}

The on/off time of the thermal units are considered with hot and cold start-up costs. These constraints are taken separately and calculated for each hour depending on the on/ off status for the next hour of the unit generation. Finally the sum of all these startup costs is added and included in the final fuel costs [25].

Off time of $n$ unit thermal generator at $t$ hour is given in Eq. (3) And at the time of $n$ unit thermal generator at $t$ hour is given in Eq. (4).

$$
T_{i, t-1}^{\text {on }} \geq T_{u i}
$$

When $T_{i, t}^{\text {off }}=1, T_{n, t}$ off

$$
T_{i, t-1}{ }^{\text {off }} \geq T_{d i}
$$

When $T_{i, t^{\text {on }}}=1, T_{n, t}{ }^{\text {on }}$

\subsubsection{Ramp constraints}

Ramp constraints determines the value of maximum power generation, can be increased or decreased for a unit $i$, at hour $t$ using in Eq. (5) and Eq. (6).

$$
\begin{gathered}
P_{i, t}-P_{i, t-1} \leq U R(i) \\
P_{i, t-1}-P_{i, t} \leq D R(i)
\end{gathered}
$$

With the above mentioned constraints UC problem is attempted in three case studies as given below.

1. The ICA algorithm is applied to a 10 unit 24 hour thermal system and the operating cost is calculated.

2. ICA is also implemented in a larger system of 40 unit 24 hours.

3. Later, stochasticity is introduced into 10 units 24 hour system using wind generation and the overall fuel cost is calculated by the wind thermal system [23].

\section{Stochastic unit commitment}

A wind generator is added to the thermal system. After this addition, there is a change in the previous unit commitment. The wind data considered here is deterministic and is assumed to be available on the specified hour, the addition of wind generator, makes the whole system stochastic. Generally, the wind fluctuates throughout the time frame, therefore the output of the wind generators cannot be 
determined. In order to integrate the renewable energy in deterministic framework, Eq. (1) is reformulated as Eq.(7). [25]

$$
\begin{aligned}
& \min \sum_{i=1}^{N} \sum_{t=1}^{T}\left[C F_{i, t}\left(P_{i, t} v_{i, t}\right)+S_{i, t} v_{i, t}\right]+ \\
& \left.M \sum_{j=1}^{N} \sum_{t=1}^{T}\left(w_{j, t}^{n}-w_{j, t}\right)\right]
\end{aligned}
$$

Such that,

$$
\begin{aligned}
& \sum_{i=1}^{N} P_{i, t}+\sum_{j=1}^{N} w_{j, t}=D_{t}(t=1,2, \ldots n) \\
& f_{k}\left(k_{i, t}\right) \leq 0, \\
& f_{c}\left(S_{i, t} v_{i, t}, k_{i, t}\right) \leq 0, \\
& 0 \leq w_{j, t} \leq w_{j, t}^{n}, \\
& k_{i, t} P_{i, \min } \leq P_{i, t} \leq k_{i, t} P_{i, \max }
\end{aligned}
$$

Where $M$ is the huge number of costlier unit, $w_{j, t}$ is the output power of wind farm at $t, w_{j, t}{ }^{n}$ is the actual power of wind generator, $P_{j, t}$ is the power generation of unit $\mathrm{i}$ at time $\mathrm{t} ; f_{k}$ is the constraint with integer variable; $f_{c}$, is the startup cost constraint and shut down cost constraint; $P_{i, \min }, P_{i, \max }$ is the minimum and maximum power limit of generator $i$ Eq. (7) has operation cost and start up and shut down costs of both thermal generators, and wind power generator. The Eq. (8) denotes power balance constraints; and Eq. (9) indicates minimum on and off time constraint and the $f_{c}$ in Eq. (10) denotes the startup and shut down cost constraint; Eqs. (9) and (10) represents the minimum and maximum power limits of both wind and thermal generators.

An additional ramp constraint is included, to consider the wind power generation (WPG) in the existing system i.e. Maximum up and down ramp constraint of the unit. This gives the maximum value of power generation that can be increased or decreased for a unit $i$ at hour $t$. [25].

$$
\begin{aligned}
& U R_{\text {max }}=d \times P_{i, \text { max }} \\
& D R_{\text {max }}=d \times P_{i, \text { min }}
\end{aligned}
$$

The ramping up or down constraint of the unit is shown below in Eq. (15) and Eq. (16),

$$
\begin{aligned}
U R i(t) & =\min \left\{U R_{i, \text { min }}, P_{i, \text { max }}-P_{i, t}\right\} \\
\operatorname{DRi}(t) & =\min \left\{D R_{i, \text { max }}, P_{i, t}-P_{i, \text { min }}\right\}
\end{aligned}
$$

The wind power fluctuations are absorbed by the system ramping capacity using Eq. (17) and Eq. (18)

$$
\begin{aligned}
& P_{w 1}(t)-P_{w 1}(t-1) \leq \operatorname{TDR}(t), \\
& \text { if } P_{w 1}(t-1)<P_{w 1}(t) \\
& P_{w 1}(t-1)-P_{w 1}(t) \leq \operatorname{TUR}(t) \\
& \text { if } P_{w 1}(t)<P_{w 1}(t-1)
\end{aligned}
$$

The wind generation is committed only when the available wind generation satisfies the ramp constraint of the system, [17]. Where $P_{w l}(t)$ is the wind power at time $t, T D R(t)$ is the total ramping down at time t, TUR $(t)$ is the total ramping up time at time t, $P_{w l}(t-1)$ is the wind power at time $t-1$.

\section{Imperialistic competitive algorithm (ICA)}

ICA is the global search algorithm based on the concept of imperialism and colonialism. In recent years, many optimization problems are solved using imperialistic competitive algorithms. The algorithm starts with the initialization of random values called countries. In this cost function used to find the power of each country. Based on the imperialist power, empire and colonies are selected. This power is inversely proportional to cost. In the next step, imperialistic competition begins. During competition, weaker empires are neglected and positions are collapsed and positions are updated. This may lead to converge to a state with one empire [39-49].

In this there are two operators, assimilation helps the colony to move towards an imperialist state in the search space with different direction, revolution arbitrary changes that occur in position of some countries. During this two process a colony with better position may get a chance to become imperialists. At the last imperialistic competition begin and all imperialists compete each other. Finally, the weak empires are neglected and competition begins until a stopping condition satisfied.

The followings are the step by step procedure used in ICA.

Step 1: Initial population called countries should be created in $\mathrm{N}$ dimensional space as

Country $I=\left[x_{i 1}, x_{i 2 .}, \ldots . ., x_{i N}\right]$ where $i=1,2, . . N$

$$
\text { Cost } k=f(\text { Countryk) }
$$

Step 2: Based on the cost function, the most powerful countries is chosen as imperialists and others countries as colonies. Where $\mathrm{N}_{\mathrm{imp}}$ are imperialists and $\mathrm{N}_{\text {col }}$ are colonies. The selected 
colonies allocate themselves between the imperialists based on the power. i.e normalized cost of imperialist power.

Step 3: The imperialistic power and cost function is reciprocal to one another such that the imperialist with least cost value is more powerful and has maximum number of colonies. After a random allocation of the colonies to imperialists, colonies with the related imperialist establishes cost of empires using Eq. (20).

$$
I C_{i}=i c_{k}-\max _{k}\left\{i c_{k}\right\}
$$

Where $i c_{k}$ is the $k^{\text {th }}$ imperialist cost and $I C_{i}$ is normalized cost. The normalized power of each imperialist is defined in Eq. (21).

$$
P_{i}=\left|\frac{I C_{i}}{\sum_{i=1}^{N_{i m p}} i c_{i}}\right|
$$

The initial number of colonies of an empire will is given in Eq. (22).

$$
N_{i}=\operatorname{round}\left\{P_{i} . N_{c o l}\right\}
$$

Where $N_{i}$ is the initial number of colonies of empires $i$ and where $i=1 \ldots N_{i m p}$.

Step 4: The imperialists start to improve their colonies based on normalized power. The colonies moved toward their relevant imperialist with the aim of searching optimal surface. To improve the searching process of the algorithm, the position is updated with the deviation from the original direction. The original position is given as Eq. (23) and updated position is given in Eq. (24).

$$
\begin{aligned}
& P_{o s} N_{i}=\operatorname{round}\left\{P_{i \cdot N_{c o l}}\right\} \\
& C_{d+1}=P_{o s C d}+\beta\left(P_{o s I} \leftarrow P_{o s C d}\right) \cdot \operatorname{rand}(0,1)
\end{aligned}
$$

Where $C_{d+1}$ is the updated position of the $d t h$ imperialist, rand is random number chosen between $(0,1), \beta$ is the weight factor, and $P_{\text {osId }}$ is the position of $d_{t h}$ imperialist. $P_{o s C d}$ is the position of $d_{t h}$ colony. $\gamma$ is the parameter to adjust the direction deviation.

Step 6: The colonies with better position compared to their relevant imperialists in terms of cost value will enjoys the position of the imperialists and the other colonies move towards the new powerful imperialist shown in Eq. (25)

$$
T_{c n}=
$$

cost (imperialist)\& mean $\{\operatorname{Cost}$ (colonies)

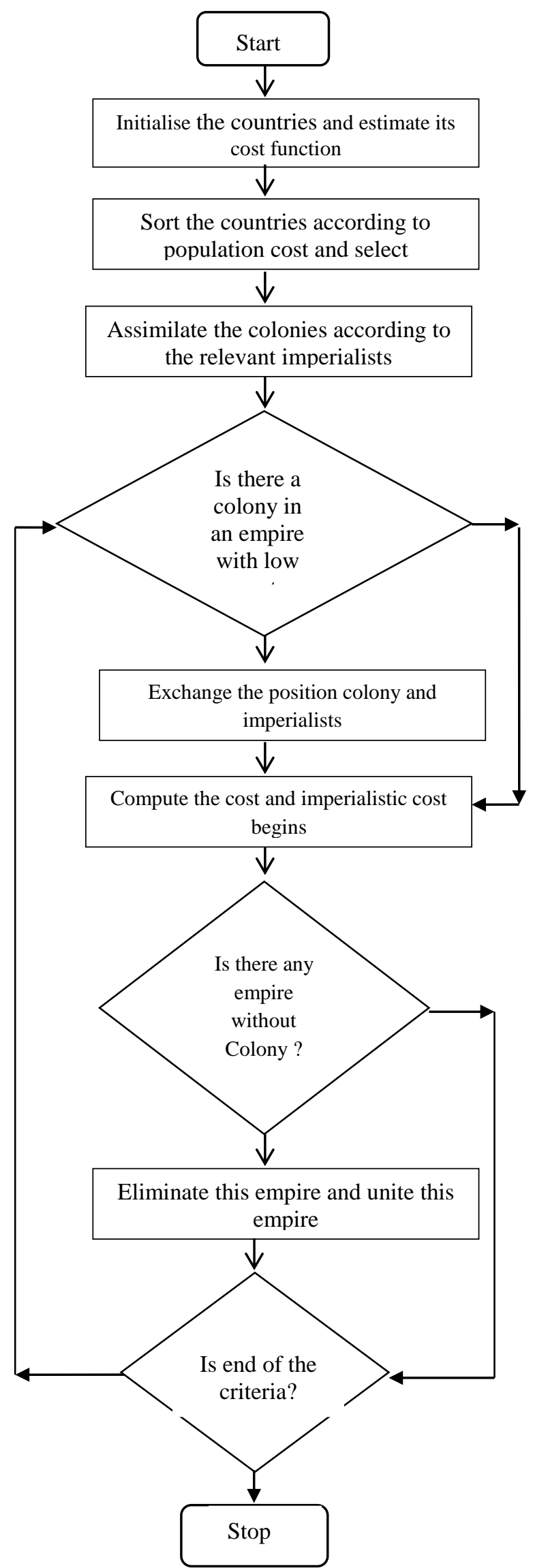

Figure.1 Flow chart for Imperialistic competitive algorithm 
Where $T_{\mathrm{cn}}$ is the total cost and $\varepsilon$ is the positive number which is less than 1 . The total cost is calculated and is defined as in Eq. (25). The constant $\varepsilon$ has the effect on the total cost and a small increase can cause the increase in the colonies role in finding the total power of empire.

Step 7: The imperialistic competition helps the powerful imperialists to gain more power and weaker empires to collapse. In such a manner, the most optimal solution (most powerful empire) gains the more chance to attract other solution toward a globally optimal solution of the problem [8]. Fig.1. shows the flowchart to solve unit commitment problem using ICA.

\section{Results}

In this section, the result of a proposed ICA algorithm discussed on IEEE 10 units 24 hour bus system., the load data for 10 units 24 hours system is shown in Table 1 and generator data for 10 units 24 hours system is shown in Table 2 .

The optimal parameters of ICA for 10 units 24 hour system is assumed to be $\mathrm{N}_{\mathrm{imp}}=10, N_{\text {col }}=200$. When some colonies are in a powerful empire, they move toward their relevant imperialist in several iterations. Some of the colonies become more nearer to the imperialists in some consecutive iterations. Therefore, they lose their search capability, and the execution time is increased until the position on the imperialist changes. To solve this issue, parameter $\gamma$ is introduced to the deviation from the original direction is set to higher values in between $30^{\circ}$ to $90^{\circ}$.

In the Table 3, the unit commitment schedule using ICA for 10 units 24 hour thermal systems using ICA are obtained. The cost is calculated for each hour using the ICA algorithm and obtained as $\$ 544733$ without including start upcost. From the Table 3, it can be observed that the cost of each hour is decreasing or increasing and do not remain constant due to continuous change in load demand. Further, ICA has been attempted on 40 unit 24 hour system. The input unit values are duplicated 4 times the values of the units of 10 units 24 hour system. The total optimization cost obtained as \$ 2928618 . The computation time comparatively better considered the size of the system. In Table. 4, 10 units 24 hour thermal systems are integrated with wind generators [25]. After this addition, there is a change in the previous unit commitment. The wind data considered here is deterministic and is assumed to be available at the specified hour. The load scheduling is obtained and the overall cost is
Table 1. Load data for 10 units 24 hour system

\begin{tabular}{|c|c|c|c|}
\hline Hour & $\begin{array}{c}\text { Load } \\
\text { (MW) }\end{array}$ & Hour & $\begin{array}{c}\text { Load } \\
\text { (MW) }\end{array}$ \\
\hline 1 & 700 & 13 & 1400 \\
\hline 2 & 750 & 14 & 1300 \\
\hline 3 & 850 & 15 & 1200 \\
\hline 4 & 950 & 16 & 1050 \\
\hline 5 & 1000 & 17 & 1000 \\
\hline 6 & 1100 & 18 & 1100 \\
\hline 7 & 1150 & 19 & 1200 \\
\hline 8 & 1200 & 20 & 1400 \\
\hline 9 & 1300 & 21 & 1300 \\
\hline 10 & 1400 & 22 & 1100 \\
\hline 11 & 1450 & 23 & 900 \\
\hline 12 & 1500 & 24 & 800 \\
\hline
\end{tabular}

Table 2. Input data for 10 units 24 hour system

\begin{tabular}{|c|c|c|c|c|c|}
\hline Unit & $\mathbf{1}$ & $\mathbf{2}$ & $\mathbf{3}$ & $\mathbf{4}$ & $\mathbf{5}$ \\
\hline $\begin{array}{c}\text { Pmax } \\
\text { MW }\end{array}$ & 455 & 455 & 130 & 130 & 162 \\
\hline $\begin{array}{c}\text { Pmin } \\
\text { MW }\end{array}$ & 150 & 150 & 20 & 20 & 25 \\
\hline A & 0.00048 & 0.00031 & 0.002 & 0.0021 & 0.00398 \\
\hline B & 16.19 & 17.26 & 16.6 & 16.5 & 19.7 \\
\hline C & 1000 & 970 & 700 & 680 & 450 \\
\hline Tioff & 8 & 8 & 5 & 5 & 6 \\
\hline Tion & 8 & 8 & 5 & 5 & 6 \\
\hline HSCi & 4500 & 5000 & 550 & 560 & 900 \\
\hline CSCi & 9000 & 10000 & 1100 & 1120 & 1800 \\
\hline CSTi & 5 & 5 & 4 & 4 & 4 \\
\hline Ini.Si & 8 & 8 & -5 & -5 & -6 \\
\hline
\end{tabular}

\begin{tabular}{|c|c|c|c|c|c|}
\hline Unit & $\mathbf{6}$ & $\mathbf{7}$ & $\mathbf{8}$ & $\mathbf{9}$ & $\mathbf{1 0}$ \\
\hline $\begin{array}{c}\mathrm{P}_{\mathrm{i}, \max } \\
\mathrm{MW}\end{array}$ & 80 & 85 & 55 & 55 & 55 \\
\hline $\begin{array}{c}\mathrm{P}_{\mathrm{i}, \mathrm{min}}, \\
\mathrm{MW}\end{array}$ & 20 & 25 & 10 & 10 & 10 \\
\hline $\mathrm{A}$ & 0.00712 & 0.00079 & 0.00413 & 0.0022 & 0.00173 \\
\hline $\mathrm{B}$ & 22.26 & 27.74 & 25.92 & 27.27 & 27.79 \\
\hline $\mathrm{C}$ & 370 & 480 & 660 & 665 & 670 \\
\hline $\mathrm{T}_{\mathrm{i}, \text { off }}$ & 3 & 3 & 1 & 1 & 1 \\
\hline $\mathrm{T}_{\mathrm{i}, \text { on }}$ & 3 & 3 & 1 & 1 & 1 \\
\hline $\mathrm{HSC}_{\mathrm{i}}$ & 170 & 260 & 30 & 30 & 30 \\
\hline $\mathrm{CSC}_{\mathrm{i}}$ & 340 & 520 & 60 & 60 & 60 \\
\hline $\mathrm{CST}_{\mathrm{i}}$ & 2 & 2 & 0 & 0 & 0 \\
\hline $\mathrm{Ini}_{\mathrm{Si}}$ & -3 & -3 & -2 & -1 & -1 \\
\hline
\end{tabular}

$\$ 482246.2$. There will be lots of scope in the future for the application of this algorithm for various optimization techniques.

In Table. 5 results of 10 units and 24 hours system including start-up cost with a thermal unit alone are compared with other algorithms and it is found that the total operation cost of ICA algorithm is $\$ 550193$ which is less compared to other given algorithms as shown in Table 5. It is noted that, 
Table 3. Load scheduling (MW) for deterministic load

\begin{tabular}{|c|c|c|c|c|c|c|c|c|c|c|c|c|}
\hline Hour & $\mathbf{P 1}$ & $\mathbf{P 2}$ & $\mathbf{P 3}$ & $\mathbf{P 4}$ & $\mathbf{P 5}$ & $\mathbf{P 6}$ & $\mathbf{P 7}$ & $\mathbf{P 8}$ & $\mathbf{P 9}$ & $\mathbf{P 1 0}$ & $\begin{array}{c}\text { Load } \\
\text { MW }\end{array}$ & $\mathbf{F C}(\mathbf{\$})$ \\
\hline 1 & 455 & 245 & 0 & 0 & 0 & 0 & 0 & 0 & 0 & 0 & 700 & 13683.1 \\
\hline 2 & 455 & 295 & 0 & 0 & 0 & 0 & 0 & 0 & 0 & 0 & 750 & 14554.5 \\
\hline 3 & 455 & 395 & 0 & 0 & 0 & 0 & 0 & 0 & 0 & 0 & 850 & 16301.9 \\
\hline 4 & 455 & 365 & 130 & 0 & 0 & 0 & 0 & 0 & 0 & 0 & 950 & 18668.8 \\
\hline 5 & 455 & 415 & 130 & 0 & 0 & 0 & 0 & 0 & 0 & 0 & 1000 & 19543.9 \\
\hline 6 & 455 & 385 & 130 & 130 & 0 & 0 & 0 & 0 & 0 & 0 & 1100 & 21879.3 \\
\hline 7 & 455 & 435 & 130 & 130 & 0 & 0 & 0 & 0 & 0 & 0 & 1150 & 22755 \\
\hline 8 & 455 & 455 & 130 & 130 & 30 & 0 & 0 & 0 & 0 & 0 & 1200 & 24150.3 \\
\hline 9 & 455 & 455 & 130 & 130 & 130 & 0 & 0 & 0 & 0 & 0 & 1300 & 26184 \\
\hline 10 & 455 & 455 & 130 & 130 & 162 & 68 & 0 & 0 & 0 & 0 & 1400 & 28768.2 \\
\hline 11 & 455 & 455 & 130 & 130 & 162 & 80 & 38 & 0 & 0 & 0 & 1450 & 30583.2 \\
\hline 12 & 455 & 455 & 130 & 130 & 162 & 80 & 33 & 55 & 0 & 0 & 1500 & 32542.4 \\
\hline 13 & 455 & 455 & 130 & 130 & 162 & 68 & 0 & 0 & 0 & 0 & 1400 & 28768.2 \\
\hline 14 & 455 & 455 & 130 & 130 & 130 & 0 & 0 & 0 & 0 & 0 & 1300 & 26184 \\
\hline 15 & 455 & 455 & 130 & 130 & 30 & 0 & 0 & 0 & 0 & 0 & 1200 & 24150.3 \\
\hline 16 & 455 & 335 & 130 & 130 & 0 & 0 & 0 & 0 & 0 & 0 & 1050 & 21005.2 \\
\hline 17 & 455 & 415 & 130 & 0 & 0 & 0 & 0 & 0 & 0 & 0 & 1000 & 19543.9 \\
\hline 18 & 455 & 385 & 130 & 130 & 0 & 0 & 0 & 0 & 0 & 0 & 1100 & 21879.3 \\
\hline 19 & 455 & 455 & 130 & 130 & 30 & 0 & 0 & 0 & 0 & 0 & 1200 & 24150.3 \\
\hline 20 & 455 & 455 & 130 & 130 & 162 & 68 & 0 & 0 & 0 & 0 & 1400 & 28768.2 \\
\hline 21 & 455 & 455 & 130 & 130 & 130 & 0 & 0 & 0 & 0 & 0 & 1300 & 26184 \\
\hline 22 & 455 & 385 & 130 & 130 & 0 & 0 & 0 & 0 & 0 & 0 & 1100 & 21879.3 \\
\hline 23 & 455 & 445 & 0 & 0 & 0 & 0 & 0 & 0 & 0 & 0 & 900 & 17177.9 \\
\hline 24 & 455 & 45 & 0 & 0 & 0 & 0 & 0 & 0 & 0 & 0 & 800 & 15427.4 \\
\hline Total cost(\$544733 & & & & & & & & & \\
\hline
\end{tabular}

Table 4. Load scheduling (MW) for system with wind generator

\begin{tabular}{|c|c|c|c|c|c|c|c|c|c|c|c|c|c|}
\hline Hour & P1 & P2 & P3 & P4 & P5 & P6 & P7 & P8 & P9 & P10 & $\begin{array}{c}\text { Load } \\
\text { MW }\end{array}$ & $\begin{array}{c}\text { Wind } \\
\text { MW }\end{array}$ & FC (\$) \\
\hline 1 & 388 & 150 & 0 & 0 & 0 & 0 & 0 & 0 & 0 & 0 & 700 & 162 & 10920 \\
\hline 2 & 438 & 150 & 0 & 0 & 0 & 0 & 0 & 0 & 0 & 0 & 750 & 162 & 11749.3 \\
\hline 3 & 455 & 244 & 0 & 0 & 0 & 0 & 0 & 0 & 0 & 0 & 850 & 151 & 13665.7 \\
\hline 4 & 455 & 327 & 0 & 0 & 0 & 0 & 0 & 0 & 0 & 0 & 950 & 168 & 15113 \\
\hline 5 & 455 & 384 & 0 & 0 & 0 & 0 & 0 & 0 & 0 & 0 & 1000 & 161 & 16109.4 \\
\hline 6 & 455 & 371 & 130 & 0 & 0 & 0 & 0 & 0 & 0 & 0 & 1100 & 144 & 18773.9 \\
\hline 7 & 455 & 397 & 130 & 0 & 0 & 0 & 0 & 0 & 0 & 0 & 1150 & 168 & 19228.7 \\
\hline 8 & 455 & 447 & 130 & 0 & 0 & 0 & 0 & 0 & 0 & 0 & 1200 & 168 & 20104.8 \\
\hline 9 & 455 & 437 & 130 & 130 & 0 & 0 & 0 & 0 & 0 & 0 & 1300 & 148 & 22790.1 \\
\hline 10 & 455 & 455 & 130 & 130 & 117 & 0 & 0 & 0 & 0 & 0 & 1400 & 113 & 25915.1 \\
\hline 11 & 455 & 455 & 130 & 130 & 146 & 20 & 0 & 0 & 0 & 0 & 1450 & 114 & 27334.8 \\
\hline 12 & 455 & 455 & 130 & 130 & 162 & 43 & 0 & 0 & 0 & 0 & 1500 & 125 & 28192 \\
\hline 13 & 455 & 455 & 130 & 130 & 88 & 0 & 0 & 0 & 0 & 0 & 1400 & 142 & 25320.2 \\
\hline 14 & 455 & 437 & 130 & 130 & 0 & 0 & 0 & 0 & 0 & 0 & 1300 & 148 & 22790.1 \\
\hline 15 & 455 & 389 & 130 & 130 & 0 & 0 & 0 & 0 & 0 & 0 & 1200 & 96 & 21949.3 \\
\hline 16 & 455 & 393 & 130 & 0 & 0 & 0 & 0 & 0 & 0 & 0 & 1050 & 72 & 19158.7 \\
\hline 17 & 455 & 373 & 130 & 0 & 0 & 0 & 0 & 0 & 0 & 0 & 1000 & 42 & 18808.7 \\
\hline 18 & 455 & 343 & 130 & 130 & 0 & 0 & 0 & 0 & 0 & 0 & 1100 & 42 & 21144.9 \\
\hline 19 & 455 & 432 & 130 & 130 & 0 & 0 & 0 & 0 & 0 & 0 & 1200 & 53 & 22702.5 \\
\hline 20 & 455 & 455 & 130 & 130 & 147 & 20 & 0 & 0 & 0 & 0 & 1400 & 63 & 27355.7 \\
\hline 21 & 455 & 455 & 130 & 130 & 56 & 0 & 0 & 0 & 0 & 0 & 1300 & 74 & 24671.4 \\
\hline 22 & 455 & 436 & 130 & 0 & 0 & 0 & 0 & 0 & 0 & 0 & 1100 & 79 & 19911.9 \\
\hline 23 & 455 & 343 & 0 & 0 & 0 & 0 & 0 & 0 & 0 & 0 & 900 & 102 & 15392.5 \\
\hline 24 & 455 & 214 & 0 & 0 & 0 & 0 & 0 & 0 & 0 & 0 & 800 & 131 & 13143.7 \\
\hline Total $\mathbf{c o s t} \mathbf{( \$ ) 4 8 2 2 4 6 . 2}$ & \multicolumn{7}{|l|}{} \\
\hline
\end{tabular}


except ICA, all the other costs are in the range of $\$ 560000$ to $\$ 567000$.

In case of 40 units 24 hour system total optimization cost obtained as \$ 2928618. The compiling time is also comparatively moderate considering the size of the system.

Another study of 10 units 24 hour system with wind generator, found that the total cost of generation in each hour is reduced to turn off the some of the costlier generators, with the integration of wind generator. Thus the proposed ICA solves the stochastic problem as well as in deterministic method and overall cost of the system is reduced and there is an increase in reliability. In the Table 6 the fuel costs of the wind, thermal systems using various algorithms are shown.

It can be inferred that the cost is least when Imperialistic Competitive Algorithm (ICA) is applied to the wind thermal system. Wind operating cost is assumed to be $2 \%$ of the total system operating cost [25].

The optimized fuel cost, thus obtained from this algorithm for the wind, thermal system is \$499092.32.

The selection process ICA is based on probabilities this makes the result better than the other algorithm [50]

There will be lots of scope in the future for the application of this algorithm for large systems with a few more modifications.

\section{Conclusion}

In this paper an imperialistic competitive Algorithm has been attempted for solving the unit commitment problem with and without wind unit. The results show the superiority of the algorithm in terms of computational efficiency in solving the unit commitment problem in both cases. Further, it can be noted from the results that the algorithm outperforms lagrangian relaxation (LR), genetic algorithm (GA), bacterial foraging (BFOA), shuffled frog leaping algorithm (SFLA), Invasive weed optimization (IWO), Particle swarm optimization (PSO) used in the literature. Therefore, it is clear that ICA algorithm is efficient in solving the unit commitment problem for scheduling power generations in both deterministic and stochastic approaches. This problem is attempted with minimum up time, down time constraint, start-up constraint, ramp up and ramp down constraint. This problem can also be attempted with more number of constraints, including multiple renewable energy sources.
Table 5. Validation of ICA on the thermal system alone (10 unit 24 hours)

\begin{tabular}{|c|c|c|c|}
\hline Method & $\begin{array}{c}\text { Start-up } \\
\text { cost } \mathbf{( \$ )}\end{array}$ & $\begin{array}{c}\text { Total } \\
\text { Operational } \\
\text { cost(\$) }\end{array}$ & $\begin{array}{c}\text { Total } \\
\text { Production } \\
\text { Cost } \mathbf{( \$ )}\end{array}$ \\
\hline GA [51] & - & - & 565825 \\
\hline PSO [51] & 2095 & 562899 & 565804 \\
\hline HPSO[51] & 4090 & 559852.3 & 563942.3 \\
\hline SFLA[51] & 4090 & 559847.7 & 563937.7 \\
\hline IWO[51] & 4790 & 557495 & 562285 \\
\hline ICA [51] & 5460 & 544733 & $\mathbf{5 5 0 1 9 3}$ \\
\hline
\end{tabular}

Table 6. Validation of ICA on the wind, thermal system

\begin{tabular}{|c|c|}
\hline Method & Cost (\$) \\
\hline LR $[25]$ & 565825 \\
\hline SFLA $[25]$ & 563937.7 \\
\hline BFOA[25] & 564842 \\
\hline GA[25] & 565825 \\
\hline LR PSO[25] & 518512.308 \\
\hline ICA & $\mathbf{4 9 9 0 9 2 . 3 2}$ \\
\hline
\end{tabular}

\section{References}

[1] C. Lowery and M. O'Malley, "Impact of wind forecast error statistics upon unit Commitment", IEEE Trans. Sustain. Energy, Vol. 3, No. 4, pp. 760-768, 2012.

[2] J. Wang, A. Botterud, H.Keko, L. Carvalho, D. Issicaba, J. Sumaili, and V. Miranda., "Wind power forecasting uncertainty and unit commitment", Appl. Energy, Vol. 88, No. 11, pp. 4014-4023, 2011.

[3] Q. P. Zheng, J. Wang, and A. L. Liu, "Stochastic optimization for unit commitment-A review", IEEE Trans. Power Syst., Vol. 30, No. 4, pp. 1913-1924, 2015.

[4] S. Takriti, J. R. Birge, and E. Long, "A stochastic model for the unit commitment problem", IEEE Trans. Power Syst., Vol. 11, No. 3, pp. 1497-1508, 1996.

[5] L. Wu, M. Shahidehpour, and T. Li, "Stochastic security-constrained unit commitment", IEEE Trans. Power Syst., Vol. 22, No. 2, pp. 800-811, 2007.

[6] F. Bouffard and F. D. Galiana, "Stochastic security for operations planning with significant wind power generation", IEEE Trans. Power Syst., Vol. 23, No. 2, pp. 306-316, 2008.

[7] J. M. Morales, A. J. Conejo, and J. Perez-Ruiz, "Economic valuation of reserves in power systems with high penetration of wind power", IEEE Trans. Power Syst., Vol. 24, No. 2, pp. 900-910, 2009.

[8] A. Tuohy, P. Meibom, E. Denny, and M. O.Malley, "Unit commitment for systems with 
significant wind penetration", IEEE Trans. Power Syst., Vol. 24, No. 2, pp. 592-601, 2009.

[9] P. A. Ruiz, C. R. Philbrick, E. Zak, K. W. Cheung, and P. W. Sauer, "Uncertainty management in the unit commitment problem", IEEE Trans. Power Syst., Vol. 24, No. 2, pp. 642-651, 2009.

[10] A. Papavasiliou, S. S. Oren, and R. P. O’Neill, "Reserve requirements for wind power integration: A scenario-based stochastic programming framework", IEEE Trans. Power Syst., Vol. 26, No. 4, pp. 2197-2206, 2011.

[11] C. De Jonghe, B. F. Hobbs, and R. Belmans, "Value of price responsive load for wind integration in unit commitment", IEEE Trans. Power Syst., Vol. 29, No. 2, pp. 675-685, 2014.

[12] Y. Zhang and G. B. Giannakis, "Distributed stochastic market clearing with high-penetration wind power", IEEE Trans. Power Syst., Vol. 31, No. 2, pp. 895-906, 2016.

[13] H. Wu, M. Shahidehpour, Z. Li, and W. Tian, "Chance-constrained day ahead scheduling in stochastic power system operation", IEEE Trans. Power Syst., Vol. 29, No. 4, pp. 15831591, 2014.

[14] Q. Wang, Y. Guan, and J. Wang, "A chanceconstrained two-stage stochastic program for unit commitment with uncertain wind power output", IEEE Trans. Power Syst., Vol. 27, No. 1, pp. 206-215, 2012

[15] R. Jiang, J. Wang, and Y. Guan, "Robust unit commitment with wind power and pumped storage hydro", IEEE Trans. Power Syst., Vol. 27, No. 2, pp. 800-810, 2012.

[16] B. Hu and L. Wu, "Robust SCUC considering continuous/discrete uncertainties and quick-start units: A two-stage robust optimization with mixed integer recourse", IEEE Trans. Power Syst., Vol. 31, No. 2, pp. 1407-1419, 2016.

[17] L. Zhao and B. Zeng, "Robust unit commitment problem with demand response and wind energy", In: Proc. IEEE Power Energy Soc. General Meeting, San Diego, CA, USA, Jul. 2012, pp. 1-8.

[18] L. Fan, J. Wang, R. Jiang, and Y. Guan, "Minmax regret bidding strategy for thermal generator considering price uncertainty", IEEE Trans. Power Sys., Vol 29, No. 5, pp. 21692179, 2014.

[19] Y. Zhou, W. Hu, Y. Min, X. Xu, and Yong Li, "Modeling and Optimization of multi type power sources Stochastic Unit Commitment Using Interval Number Programming", Journal of Energy Engineering, Vol. 143, No. 5, pp. 04017036-1 - 04016037-17, 2017,
[20] Y. Liu, C. Jiang, J. Shen, and J. Hu, "Coordination of hydro units with wind power generation using interval optimization", IEEE Trans. Sustainable Energy, Vol 6, No. 2, pp. 443-453, 2015.

[21] Y. Wang, Q. Xia, and C. Kang, "Unit commitment with volatile node injections by using interval optimization", IEEE Trans. Power Sys., Vol. 26, No. 3, 1705-1713, 2011.

[22] C. Wang, F. Liu, J. Wang, F. Qiu, W.Wei, S. Mei, and S. Lei "Robust risk-constrained unit commitment with large-scale wind generation: An adjustable uncertainty set approach", IEEE Trans. Power Syst., Vol. 32, No. 1, pp. 723-733, 2017.

[23] C. Zhao and Y. Guan, "Unified stochastic and robust unit commitment", IEEE Trans. Power Syst., Vol. 28, No. 3, pp. 3353-3361, 2013.

[24] Y. Dvorkin, H. Pandzic, M. A. OrtegaVazquez, and D. S. Kirschen, "A hybrid stochastic/interval approach to transmissionconstrained unit commitment", IEEE Trans. Power Syst., Vol. 30, No. 2, pp. 621-631, 2015.

[25] B. Saravanan, S. Mishra, D. Nag, "A solution to stochastic unit commitment problem for a wind-thermal system coordination", Frontier in Energy,Vol. 8, No. 2, pp. 192-200, 2014.

[26] W. L. Snyder, Jr., H. D. Powell, Jr., and J. C. Rayburn, "Dynamic programming approach to unit commitment", IEEE Trans. Power Syst., Vol. 2, No. 2, pp. 339-347, 1987.

[27] B. Saravanan, S.Sikri, S.Das, and D.P Kothari, "A Solution to Unit Commitment Problem- a review", Frontier in EnergySpringer, Vol.7, No. 2, pp 223-236, 2013.

[28] B. Zeng, Y. An, and K. Ludwig, "Chance constrained mixed integer program: Bilinear and linear formulations, and Benders decomposition", Univ. South Florida, Tampa, FL, USA, Tech. Rep., 2014.

[29] T. Li and M. Shaheidhpour, "Price based unit commitment: a case of Langrangian relaxation versus mixed integer programming", IEEE Trans. Power Syst., Vol. 20, No. 4 pp: 20152025, 2005

[30] S. Takriti and J. R. Birge, "Lagrangian solution techniques and bounds for loosely coupled mixed-integer stochastic programs", Oper. Res., Vol. 48, No. 1, pp. 91-98, 2000.

[31] W. L. Peterson and S. R. Brammer, "A capacity based Lagrangian relaxation unit commitment with ramp rate constraints", IEEE Trans. Power Syst., Vol. 10, No. 2, pp. 1077-1084, 1995 
[32] A.I. Cohen and M. Yoshimura, "A branch-andbound algorithm for unit commitment", IEEE Trans. Power Syst., PAS-102, No.2, pp. 444451, 1983.

[33] S. A. Kazarlis, A. G. Bakirtzis, and V. Petridis, "A genetic algorithm solution to the unit commitment problem", IEEE Trans. Power Syst., Vol. 11, No. 1, pp. 83-92, 1996

[34] I. J. Raglend, C. Raghuveer, G. R. Avinash, N.P. Padhy, D.P. Kothari, "Solution to profit based unit commitment problem using particle swarm optimization", Applied Soft Computing, Vol. 10, No.4, pp. 1247-1256, 2010.

[35] M. Eslamian, S.H. Hosseinian, and B. Vahidi, "Bacterial foraging-based solution for the unitcommitment problem", IEEE Trans. Power Syst., Vol. 24, No.3 pp. 1478-1488, 2009.

[36] T. Sum-im and W. Ongsakul, "Ant colony search algorithm for unit commitment", In: Proc. of IEEE International Conference on Industrial Technology, Maribor, Slovenia, pp. $72-77,2003$

[37] D. N. Simopoulos, S.D. Kavatza, and C.D. Vournas, "Unit Commitment by an Enhanced Simulated Annealing Algorithm", IEEE Trans. Power Syst., Vol. 21, No. 1, pp. 68-76, 2006.

[38] J. Ebrahimi, S. H. Hosseinian, and G.B.Gharehpetian, "Unit Commitment Problem Solution Using Shuffled Frog Leaping Algorithm", IEEE Trans. Power System., Vol. 26, No. 2, pp. 573-581, 2011.

[39] T. Niknam, E.T Fard, N. Pourjafarian, and A. Rousta, "An efficient hybrid algorithm based on modified imperialist competitive algorithm and k-means for data clustering", Engineering Applications of Artificial Intelligence, Vol.24 No.2, pp: 306-17, 2011.

[40] H. Duan, C. Xu, S. Liu, and S. Shao, "Template matching using chaotic imperialist competitive algorithm", Pattern Recognition Letters, Vol. 31, No.13, pp.1868-75, 2010.

[41] M. Yousefi, A. Darus, and H. Mohammadi, "An imperialist competitive algorithm for optimal design of plate-fin heat exchangers", International Journal of Heat and Mass Transfer, Vol .55, No. 11, pp.3178-85, 2012.

[42] L .Coelho, L .Afonso, and P.Alotto, "A modified imperialist competitive algorithm for optimization in electromagnetics", IEEE Transactions on Magnetics, Vol .48 No. 2, pp. 579-82, 2012.

[43] A. Jalilvand, S. Behzadpoor, and M. Hashemi, "Imperialist competitive algorithm based design of pss to improve the power system stability",
In: Proc. of the 2010 joint international conference on power electronics, drives and energy systems, pp. 1-5, 2010.

[44] C. Lucas, Z .Nasiri-Gheidari, and F. Tootoonchian, "Application of an imperialist competitive algorithm to the design of a linear induction motor", Energy Conversion and Management, Vol.51, No.7, pp.1407-11, 2010.

[45] V. Rashtchi, E. Rahimpour, and H. Shahrouzi, "Model reduction of transformer detailed R-CL-M model using the imperialist competitive algorithm", International Journal of Electrical Power \& Energy Systems, Vol. 6, No.4, pp. 233-42, 2012.

[46] B. Mohammadi-ivatloo, A. Rabiee, A. Soroudi, and M. Ehsan, "Imperialist competitive algorithm for solving non-convex dynamic economic power dispatch", Energy, Vol. 44, pp. 228, 2012

[47] M.M. Hadji and B. Vahidi, "A Solution to the Unit Commitment Problem Using Imperialistic Competition Algorithm", IEEE Transactions on Power Systems, Vol. 27, No. 1, pp. 117-124, 2012.

[48] S. Talatahari, B.F. Azar, R. Sheikholeslami, and A.H.Gandomi, "Imperialist competitive algorithm combined with chaos for global optimization", Communications in Nonlinear Science and Numerical Simulation, Vol. 17, No. 3, pp. 1312-1319, 2012.

[49] E.A. Gagarin and C. Lucas, "Imperialist competitive algorithm: "An algorithm for optimization inspired by imperialistic competition", In: Proc. IEEE Congr. Evolutionary Computation, 2007.

[50] S. Nazari-Shirkouhi, H. Eivazy, R. Ghodsi, K. Rezaie, and E. Atashpaz-Gargari, "Solving the integrated product mix-outsourcing problem using the Imperialist Competitive Algorithm", International Journal of Electrical Power and Energy Systems, Vol.37 pp.7615-7626, 2010.

[51] B. Saravanan , E.R. Vasudevan, and D.P. Kothari, "Unit commitment problem solution using invasive weed optimization algorithm", International Journal of Electrical Power and Energy Systems, Vol. 55, pp. 21-28, 2014. 